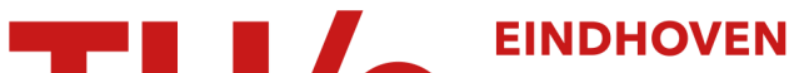 \\ UNIVERSITY OF \\ TECHNOLOGY
}

\section{Dispersion rheology at microgravity: what can it teach us?}

\section{Citation for published version (APA):}

Stein, H. N. (1993). Dispersion rheology at microgravity: what can it teach us? Advances in Colloid and Interface Science, 46, 283-295. https://doi.org/10.1016/0001-8686(93)80044-C

DOI:

10.1016/0001-8686(93)80044-C

Document status and date:

Published: 01/01/1993

\section{Document Version:}

Publisher's PDF, also known as Version of Record (includes final page, issue and volume numbers)

\section{Please check the document version of this publication:}

- A submitted manuscript is the version of the article upon submission and before peer-review. There can be important differences between the submitted version and the official published version of record. People interested in the research are advised to contact the author for the final version of the publication, or visit the $\mathrm{DOI}$ to the publisher's website.

- The final author version and the galley proof are versions of the publication after peer review.

- The final published version features the final layout of the paper including the volume, issue and page numbers.

Link to publication

\section{General rights}

Copyright and moral rights for the publications made accessible in the public portal are retained by the authors and/or other copyright owners and it is a condition of accessing publications that users recognise and abide by the legal requirements associated with these rights.

- Users may download and print one copy of any publication from the public portal for the purpose of private study or research.

- You may not further distribute the material or use it for any profit-making activity or commercial gain

- You may freely distribute the URL identifying the publication in the public portal.

If the publication is distributed under the terms of Article 25fa of the Dutch Copyright Act, indicated by the "Taverne" license above, please follow below link for the End User Agreement:

www.tue.nl/taverne

Take down policy

If you believe that this document breaches copyright please contact us at:

openaccess@tue.nl

providing details and we will investigate your claim. 
00162 A

DISPERSION RHEOLOGY AT MICROGRAVITY: WHAT CAN IT TEACH US?

\section{H.N.Stein}

Laboratory of Colloid Chemistry

Eindhoven University of Technology

P.O.Box 513, $5600 \mathrm{MB}$ Eindhoven, The Netherlands

\section{ABSTRACT}

Rheology is one of the few methods which can be used for analyzing coagulation behaviour in concentrated dispersions. This is important for handling both theoretical and practical problems. For understanding the rheological behaviour of concentrated dispersions, experiments performed under $\mu \mathrm{g}$ conditions are useful.

\section{INTRODUCTION}

Dispersion rheology is one of the few methods which can teach us something on the coagulation behaviour of concentrated dispersions. Whereas dilute dispersion can be studied by quite a number of experimental methods with theoretical interpretations based on not too unsurveyable assumptions, rheology is the principal method available for concentrated dispersions. In the present paper, the relevance of dispersion rheology for dispersion science will be highlighted both from a theoretical and from a practical point of view.

Two important fields can be distinguished: flow, and formation of particle networks. Both are important in practical as well as in theoretical respect:

In practical respect, flow is important in slurry transport (e.g. transport of powder coal; application of paint). Generally, low energy dissipation during flow is aimed at, which means that viscosity should be as low as compatible with other restrictions on the system. An even more serious problem than excessive energy dissipation may arise when the system is prone to blocking of flow by sediment or floc formation; this is especially problematic in systems in which regular flow of a suspension is to be relied upon. Flow blocking in most cases is due to formation of particle networks, by coagulation and/or sedimentation. Such particle networks are formed e.g. during formation of soils, ocean 
floors, filter beds etc. Once such networks are formed, problems may arise by their collapse (landslides, ocean floor subsidance, filter bed clogging etc.). Such practical problems are essentially connected with the rheological behaviour of the systems concerned.

In theoretical respect, dispersion rheology can teach us something on the degree of coagulation of a dispersion; this can give valuable clues on the forces acting between the suspended particles. Indeed, from rheological data, the force can be calculated which is necessary to separate two contacting particles.

In this paper, some examples will be discussed, with regard to both practical and theoretical consequences for dispersion behaviour. The theoretically interesting points are highlighted in the sections 1 and 3 , while sections 2 and 4 deal with more practical problems.

\section{INFLUENCE OF COAGULATION ON RHEOLOGY}

This will be illustrated by experiments with rather large $(43 \mathrm{~mm})$ glass spheres in organic media [1].

Glass is by nature a hydrophilic solid, but it can be made hydrophobic e.g. by silanization. This difference is reflected in the rheology of dispersions of glass spheres in organic media of different polarities: e.g. di-octylphthalate (DOP) as an apolar medium, glycerol-water mixtures as a polar medium, and di-methoxyglycol-phthalate (DMGP) with intermediate polarity. "Polarity" of a liquid is used frequently as an intuitive concept; it should be noted, however, that in the cases at hand, it can be correlated with thermodynamic properties of the liquids concerned (partial molar excess Gibbs free energy of water in the media [2,3]). Such dispersions are in most cases Newtonian or shear thinning, depending on their solid volume fraction $\phi$; and their rheological behaviour can be described, at not too small shear rates, in good approximation by:

$$
\tau=\tau_{B}+\eta_{i n f} \cdot \dot{\gamma}
$$

In this relation, $\tau_{\mathrm{B}}$ is an extrapolated yield value, and expresses in first approximation deviations from Newtonian behaviour; $\eta_{\text {inf }}$ is the limiting viscosity for $\dot{\gamma} \Rightarrow \infty$.

Dispersions of hydrophilic glass in a polar medium do not show distinct signs of coagulation: no distinct flocs can be discerned visually in such dispersions, and $\tau_{\mathrm{B}}$ remains close to 0 up to quite substantial volume fractions of solid $(\phi \approx 0.35)$ where 
important hydrodynamic interactions between the dispersed particles are expected (see fig.1).

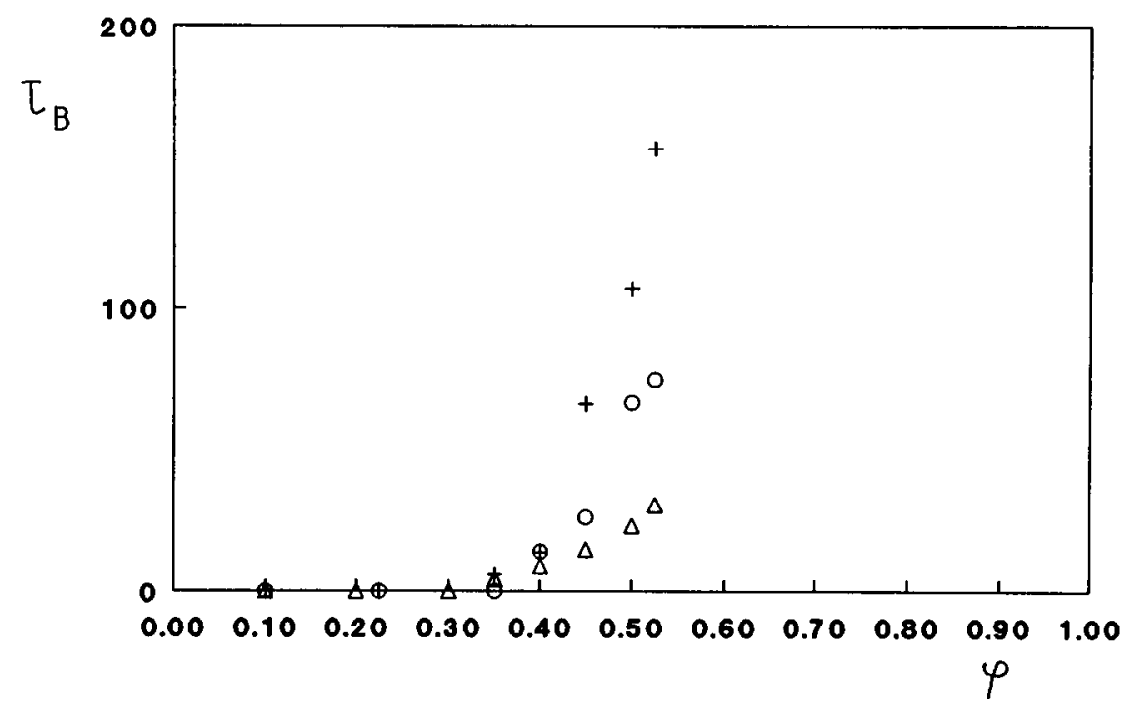

Figure 1

Extrapolated yield value $\tau_{B}\left(8 . \mathrm{cm}^{-1} \mathrm{~s}^{-2}\right)$ vs. solid volume fraction $\phi[1]$, for suspensions of native glass in: $\quad O$ dioctylphthalate;
$\Delta \quad$ di-methoxyglycolphthalate;
$+\quad$ glycerol-water mixture.

Since the dispersions contain large dispersed particles in which London-van der Waals attraction may be assumed to be of small importance only, the absence of coagulation does not come as a surprise.

Neither do dispersions of hydrophilic glass in an apolar medium show distinct signs of coagulation, by the same criteria as mentioned above:

a) floc formation is not observed visually;

b) $\tau_{\mathrm{B}}$ starts to deviate from 0 at the same solid volume fraction $\phi \approx 0.35$, independent of the polarity of the medium;

c) At $\phi>0.35$, there are differences between the $\tau_{\mathrm{B}}$ values in different media, but these are connected with differences in the viscosities of the media, not with differences in their polarity. 
Thus, the sequence of the viscosities of the media is glycerol $>$ DOP $>$ DMGP, whereas the sequence in their polarity is glycerol $>$ DMGP $>$ DOP; and the rise of the dispersion $\tau_{B}$ values with increasing $\phi$ values follows the former sequence, not the latter. Similarly, if we divide the $\tau_{\mathrm{B}}$ values through the medium viscosities $\eta_{\mathrm{inf}}$ and plot the resulting quantity vs. the solid volume fraction $\phi$, we obtain one single curve. Thus, $\tau_{B}$ appears to be proportional to the viscosity of the medium, rather than related to its polarity.

The relative viscosity $\eta_{\text {inf }} / \eta_{0}$ is found to be independent of the polarity of the medium (see fig.2); this comes down to the statement that the viscosity of the suspensions concerned is proportional to the viscosity of the dispersion medium.

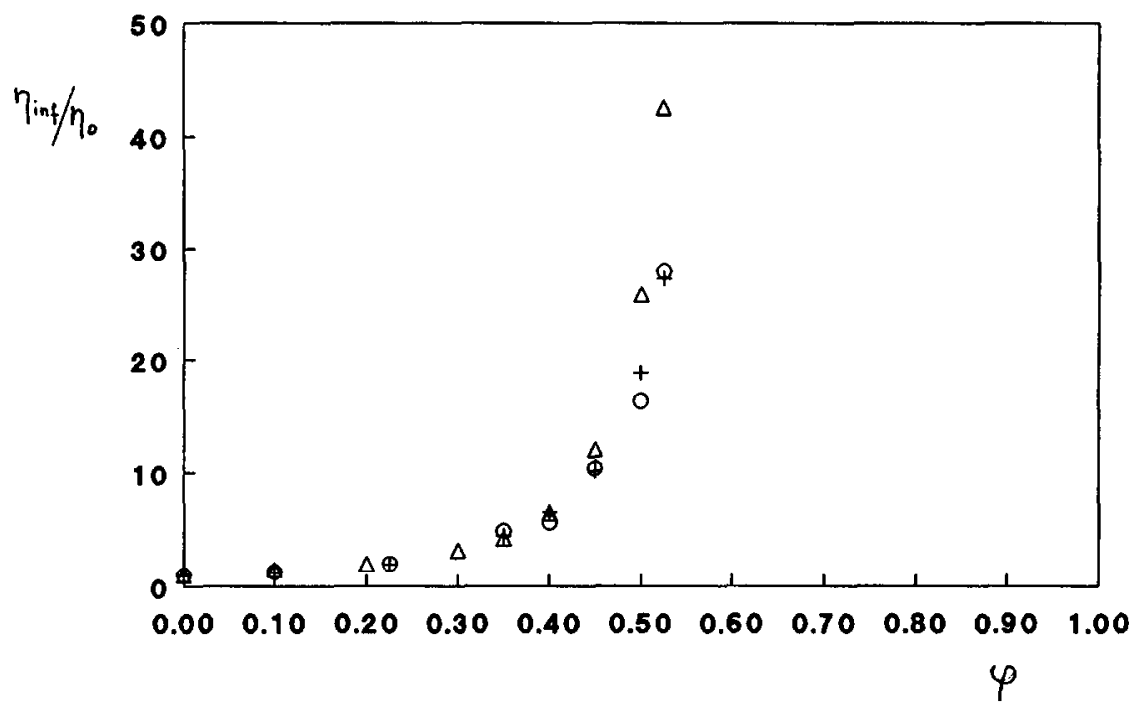

Figure 2

Relative viscosities $\left(\eta_{\text {ing }} / \eta_{a}\right)$ vs. solid volume fraction [1], for suspensions of native glass. Media indicated by the same symbols as in fig.1.

With hydrophobic glass, however, different phenomena are observed especially for $\tau_{\mathrm{B}}$. Strong coagulation is found in polar media, in spite of the large size of the particles concerned. This is apparent from the following facts:

a) visually flocs can be discerned;

b) in suspensions of hydrophobic glass particles in a polar medium, $\tau_{\mathrm{B}}$ starts to deviate from 0 at very low $\phi$ values $(\phi \approx 0.1)$, at which a pronounced hydrodynamic 
interaction is not yet expected (see fig.3). The $\phi$ values at which $\tau_{\mathrm{B}}$ starts to deviate from 0 shift to higher values with decreasing polarity of the medium; and in dispersions of hydrophobic glass in an apolar medium $\tau_{\mathrm{B}}$ deviates from 0 again at $\phi \approx 0.35$, just as dispersions of hydrophilic particles. In the context of the present paper it is especially important that once $\tau_{B}$ starts to deviate from 0 , its increase is proportional to the viscosity of the medium, not to its polarity.

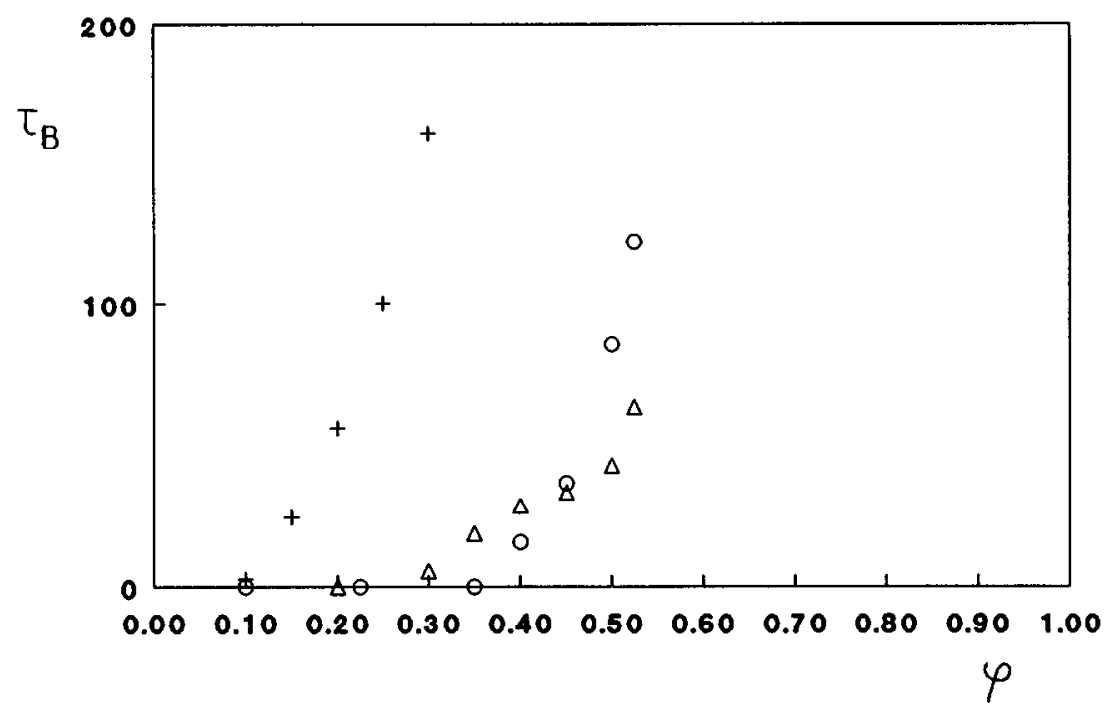

Figure 3

Extrapolated yield values vs. solid volume fraction in suspensions of silanized glass in different media, indicated as in fig.1 [1].

This leads to a crossing of the $\tau_{\mathrm{B}}(\phi)$ curves (see fig.3). However, the curves can be disentangled by dividing them by the viscosity of the medium concerned $\eta_{\mathrm{o}}$ (fig.4). Thus, again, $\tau_{\mathrm{B}}$ is found to be proportional to $\eta_{\mathrm{o}}$.

No distinct differences are found between dispersions of hydrophobic glass particles in the media concerned with regard to $\eta_{\text {inf }} / \eta_{0}$, in spite of different coagulation behaviours. This means in the first place that at the highest shear rate applied in the experiments, all coagulation structures present at rest are destroyed (only at low $\phi$ values some of the structure appears to be remnant, as shown by slightly higher viscosites in a polar than in an apolar medium). In addition, in the suspensions concerned, $\eta_{\text {inf }}$ again is found to be 
proportional to the viscosity of the medium; for it is the relative viscosity, $\eta / \eta_{0}$, which is independent of the dispersion medium.

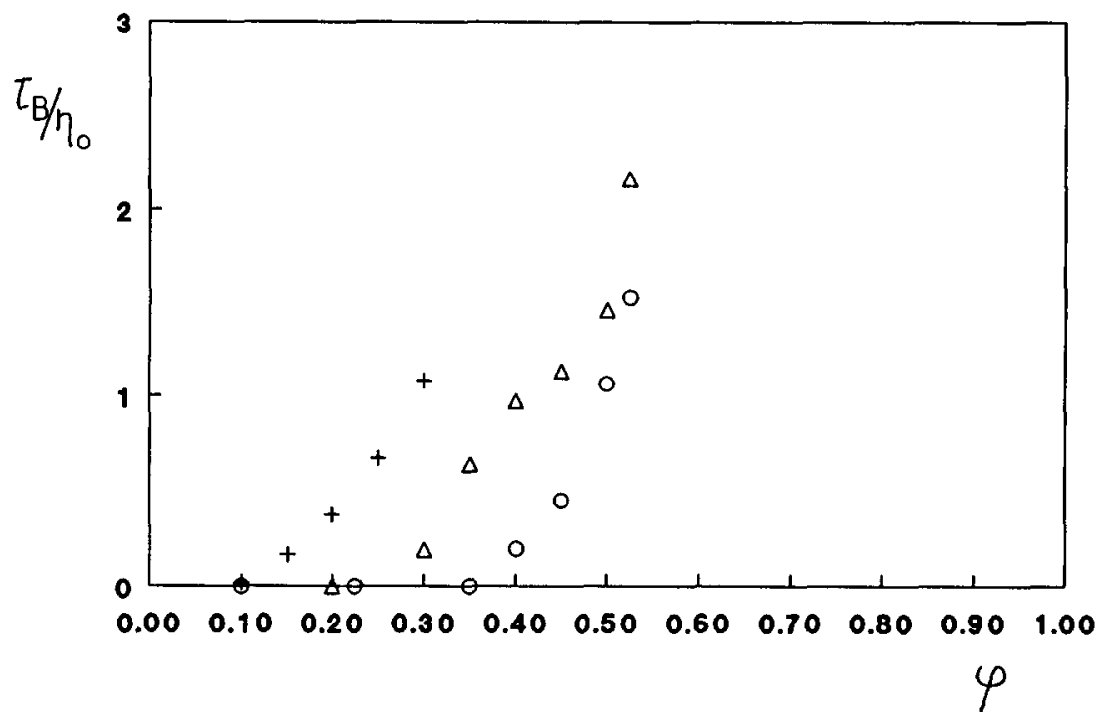

Figure 4

$\tau B / \eta o$ (s-1) vs. solid volume fraction, for dispersion of silanized glass in different media [1].

The rheological properties of dispersions of hydrophobic glass in an apolar medium do not show distinct signs of coagulation; neither is in this case coagulation observed visually.

These findings have two important consequences:

a) hydrophobic particles, of diameter $43 \mu \mathrm{m}$, in a polar medium show a pronounced tendency towards coagulation, in spite of significant London- van der Waals forces not to be expected at the particle size concerned;

b) if both $\tau_{\mathrm{B}}$ and $\eta_{\text {inf }}$ are proportional to $\eta_{\mathrm{o}}$, then the energy dissipation ( $\epsilon$ ) of the suspensions concerned, per unit of volume and time, is proportional to $\eta_{\mathrm{o}}$ as well, since:

$$
\varepsilon=\tau \cdot \dot{\gamma}=\tau \cdot \gamma+\eta^{2} \cdot \dot{\gamma}
$$

This proves that this energy dissipation is determined by overcoming the viscous drag on motion of the particles through the liquid rather than by the energy dissipated on pair 
formation and disruption. $\tau_{\mathrm{B}}$ increases with increasing degree of coagulation, but only because a particle in a coagulating suspension when moving entrains more neighbours.

\section{PREVENTION OF COAGULATION IN WATER-BASED PAINTS [4].}

In water-based paints, quite generally solid particles are added for imparting a sufficient covering power to the paint. In most cases, the solid concerned is $\mathrm{TiO}_{2}$. Coagulation of the $\mathrm{TiO}_{2}$ is to be avoided, since this increases the effective particle size. The size of the primary particles is adjusted such as to obtain an optimum light scattering, thus an increase in effective particle size diminishes the scattering efficiency of the pigment. Coagulation of the $\mathrm{TiO}_{2}$ particles frequently is prevented by adding a dispersing agent (e.g., polyacrylic acid). However, an excess of dispersion agent diminishes the water resistance of the coating finally formed and thus is to be avoided as well.

The dispersions concerned are much too concentrated to apply light scattering as a means of checking the degree of dispersion of the pigment. However, this can be done by rheology. Figure 5 shows the viscosity as a function of $\log$ (shear rate) in dispersions of $\mathrm{TiO}_{2}$ with different concentrations of dispersant (polyacrylic acid, molecular weight 2000 ), at a $\mathrm{pH}=7.4$. The dispersion in the absence of polyacrylic acid is near its IEP and therefore is coagulated; this is borne out by its shear thinning character. Addition of polyacrylic acid at first increases the viscosity and promotes the shear thinning character; this can be understood by bridging coagulation effected by the polyacrylic acid. Addition of more polyacrylic acid decreases the viscosity and makes the shear thinning character of the dispersion less pronounced. The viscosity reaches a minimum at a given concentration of the polyacrylic acid, and this minimum can be taken as the minimum amount of polyacrylic acid necessary to prevent coagulation. Since an excess of polyacrylic acid is, for other reasons, to be avoided, the minimum in the viscosity vs. concentration graph is also the optimum amount of polyacrylic acid to be used. 


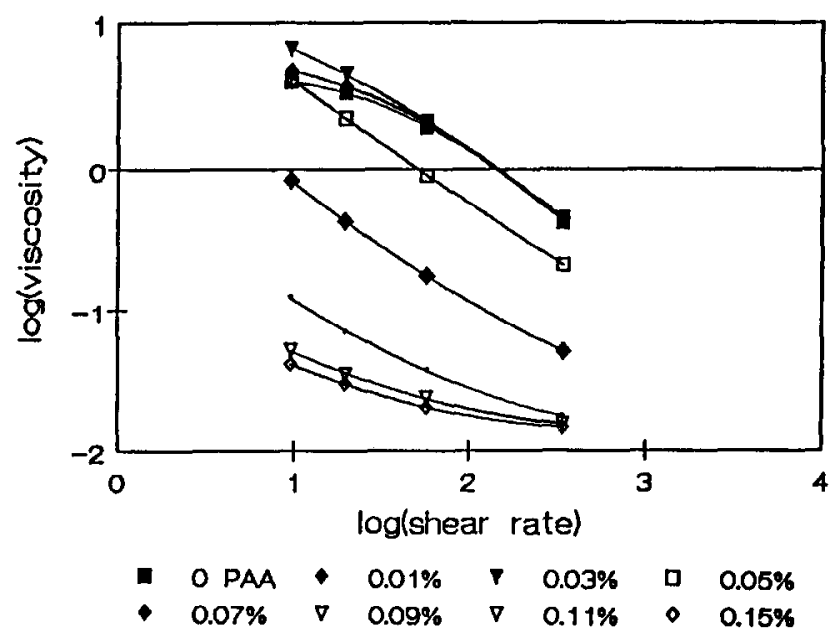

Figure 5

$\log \left(\right.$ viscosity) vs. $\log (\dot{\gamma})$ in suspensions of $\mathrm{TiO}_{2}$ in water, with polyacrylic acid (PAA, MW. 2000) added; quantities of PAA expressed in weight-\% of PAA, 0.2 weight-\% corresponds with $2 * 10^{4}$ g per $\mathrm{m}^{2} \mathrm{TiO}_{2}$ surface.

\section{ANALYSIS OF RHEOLOGICAL DATA FOR FORCES BETWEEN PARTICLES:} THE GIANT FLOC MODEL [5].

The remarkable result reported in par. 1 above, that even dispersions of quite large particles (glass spheres, $43 \mu \mathrm{m}$ diameter) can show coagulation, makes it desirable to calculate the attractive force between the particles; since the first step to understand an unexpected phenomenon is to quantitatively characterize it. For doing this, the so-called Giant Floc model has been developed for the rheology of concentrated coagulating suspensions. This model starts from the following assumptions:

1. At rest, a network exists extending throughout the available volume (no separate flocs).

2. Shear is distributed uniformly only at high $\dot{\gamma}$ values; at low $\dot{\gamma}$, shear occurs predominantly in preferential shear planes separating domains (fig.6).

3. The inter-shear plane distance decreases with increasing $\dot{\gamma}$; this is the cause of shear thinning. This assumption is based on the consideration that weak points in a particle network may be able to withstand a low shear stress, but come increasingly at risk of being broken down when the shear stress increases.

4.Deformation of the gel is accompanied by relative motion of adjacent domains. 
5. On such motion, particles bordering a shear plane are forced from their straight motion, by particles of the adjacent domain. A typical deviation distance is $\delta$.

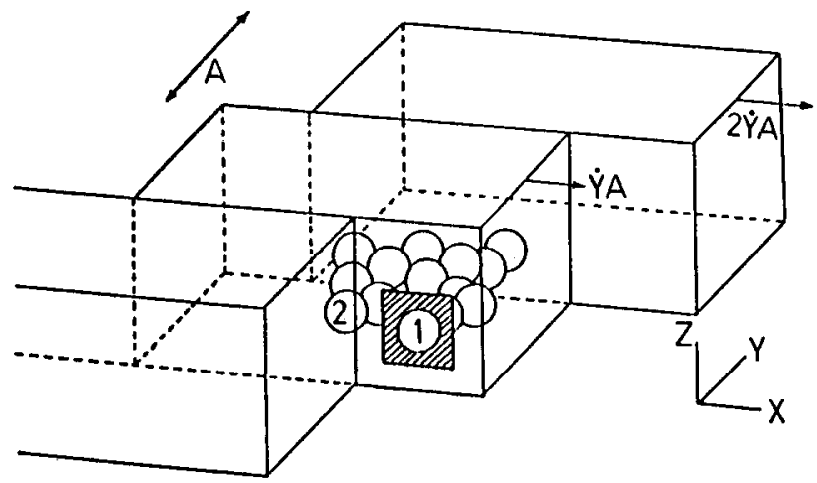

Figure 6

Schematic view of "Giant Floc" model. Three domains are shown, with their velocities relative to the foremost one. In the middle domain, part of the coagulate is indicated. Particles 1 and 2 border the same shear plane. The shaded area is the are in the shear plane associated with particale 1 [5].

6. In deviating, a particle entrains q-1 neighbours over distance $\delta .1$ (with $0<1<1$ ). q is the average number of nearest neighbours in the undisturbed particle network.

7. At $\gamma \Rightarrow \infty$, the interplanar distance approaches the particle diameter $2 \mathrm{~b}$.

8. This condition is reached when the differential viscosity, $\mathrm{d} \tau / \mathrm{d} \dot{\gamma}$, becomes independent of coagulation. The number of contacts to be broken is then given by:

$$
N_{c}=\left[\frac{\phi}{0.6046}\right]^{2} \cdot \frac{1}{4 b^{2} \sin \left(\frac{\pi}{6}\right)}
$$

In this formula, the number 0.6046 is the volume fraction of a suspension of equal-sized spheres, arranged in hexagonal close packing in planes, which can move with respect to adjacent similar planes.

The basic assumption of this model - development of shear planes in a sheared suspension of essentially uniform solid volume fraction - is consistent with data reported by Hoffman $[6,7,8]$ for non-coagulating suspensions; recently, slightly similar ideas have been reported by Uriev c.s. $[9,10]$. The model is to be distinguished from the "elastic floc" model of Hunter c.s. $[11,12,13]$ which starts from the assumption of separate flocs and is 
more appropriate at low solid volume fractions, where the solid volume fraction even in a system at rest is not homogeneous in view of the fractal nature of coagulates $[14,15]$.

Formula (3) makes possible a calculation of the force necessary to separate two contacting particles, from the shear stress necessary to reach this state.

The result of this calculation is, that in suspensions of hydrophobic glass in polar media, forces between contacting particles are operative which are larger than can be accounted for by London-van der Waals attraction. This, of course, is confirmed by the visual observation of flocs in the suspensions mentioned.

The fact that attraction is larger than London-van der Waals attraction is unexpected; but it agrees with observations on similar systems:

-direct force measurements [16]

-coagulation rates [17]

-contact angles between emulsion droplets [18]

If really an attractive interaction exists between hydrophobic particles in polar media, which significantly surpasses values expected from London-van der Waals attraction, this would have important consequences for our understanding of particle interactions. Thus, this result is important from a theoretical point of view.

\section{BLOCKING OF SLURRY TRANSPORT [19,21].}

In very concentrated slurries ( $\phi>0.55$ for monodisperse spherical particles), flow blocking phenomena may be observed. Thus, on stress controlled deformation, a maximum possible deformation ( $\left.\alpha_{\max }\right)$ is observed [19]. On a sinusoidally varying stress, a sinusoidally varying deformation is expected (when the system behaviour conforms to linear viscoelasticity). However, a certain deformation appears not to be surpassed, making the $\gamma$ (time) curve look like a "decapitated" sinus. The interpretation of this phenomenon is, that at that deformation a substantial part of the dispersed particles forms a closely packed aggregate which cannot easily be disrupted without locally increasing the overall volume of the aggregate; which is precluded because of the large solid volume fraction in the surrounding suspension.

This is to be distinguished from a superficially similar phenomenon reported by Akers and Machin [20]: These authors investigated the rheology of coagulating suspensions at much lower $\phi$ values $(\phi \approx 0.3)$. They observed in a shear controlled experiment, that a 
certain shear stress can no more be supported by the particle network; so in their experiment the $\tau$ (time) curve shows a decapitated sinus, whereas in our experiment it is the $\gamma$ (time) curve which shows such a form.

In concentrated dispersions, frequently a transition from shear-thinning to shear-thickening ("dilatancy") can be observed. In the transition region between these regimes, frequently sudden "bumbs" in the viscometer reading are seen [21] which can best be interpreted as temporary formation of regions with close packing, but which at those $\phi$ values and shear rates can still be disrupted (fig. 7, upper half). The frequency with which such bumbs appear is increased greatly by just a small increase in shear rate (fig.7, lower half). This result is, in view of the large practical problems which may arise by flow blocking, an important phenomenon both from a theoretical and from a practical point. Flow blocking phenomena can also be observed in shear rate controlled flows.
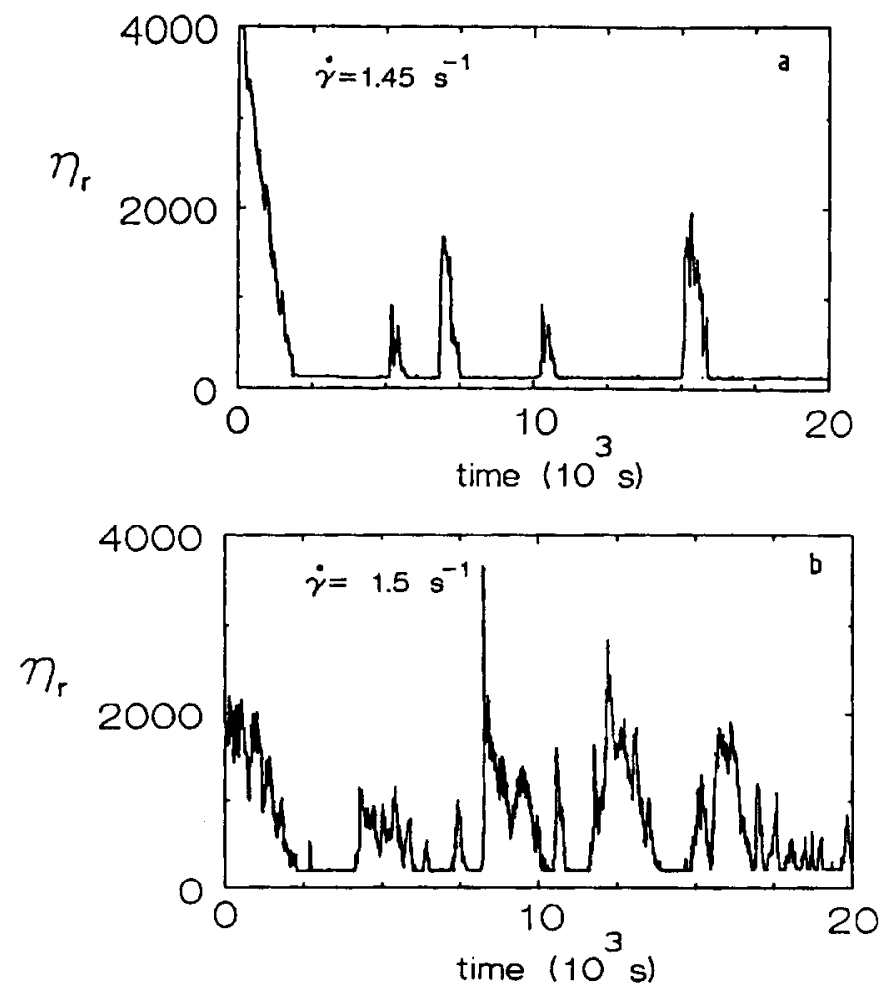

Figure 7

Time dependence of the relative viscosity of a dispersion of polystyrene in glycerol/water mixture $(86.1 \% w / w), \phi=0.585[11]$. 


\section{MICROGRAVITY AS A USEFUL TOOL IN DISPERSION RHEOLOGY}

The giant floc model, which plays such a useful role in the analysis of rheological phenomena, still needs further testing. Ideally, an experiment is required in which rheological data are combined with observations on the formation and shape of shear planes. Especially particle networks with only a low overall $\phi$ value are interesting; however, under normal gravity conditions the range of solid volume fractions in which separation of flocs can be avoided and in which no flow blocking occurs, is rather restricted $(0.35<\phi<0.45)$. This might be prevented by investigating a suspension with density matched between the dispersed and the continuous phases. However, in the first place this implies severe restrictions on the solid to be employed, at least if attention is focused on dispersions in aqueous media (most solid phases differ too much from water with regard to their density to make density matching possible). Density can be matched in aqueous dispersions of polystyrene; but because of the large refractive index difference between the dispersed and continuous phases in such suspensions, the resulting dispersions are turbid and do not permit visual observation of developing shear planes. Such an experiment requires (nearly) matching of refractive indices between the dispersed and continuous phases. However, then the density of these phases cannot be matched, and at low solid volume fractions, at $1 \mathrm{~g}$, formation of separate flocs will prevent the formation of a particle network extending throughout the available volume. Under $\mu \mathrm{g}$ conditions, however, this could be prevented.

\section{CONCLUSION}

An experiment in which low solid volume fraction particle networks are investigated both rheologically and visually, without separation of flocs, requires microgravity conditions. Such an experiment is theoretically interesting for analysis of the rheological data with regard to interaction forces between dispersed particles; such an understanding is important in practical respect as well, in view of the practical importance of dispersion flow.

\section{REFERENCES}

[1] A.J.G.van Diemen, F.W.A.M.Schreuder and H.N.Stein, J.Coll. Int. Sci. 104 (1985) 87. 
[2] P.P.van Mierlo and H.N.Stein, J. Coll. Int. Sci. 127 (1989) 583.

[3] P.P.van Mierlo and H.N.Stein, J.Chem.Eng.Data 34 (1989) 84.

[4] S.G.Heijman, Verfkroniek 63 (1990) 463; "Dispersion of oxide pigments in water: the colloid chemistry point of view", Ph. D. thesis, Eindhoven (in preparation).

[5] F.W.A.M.Schreuder and H.N.Stein, Rhcologica Acta 26 (1987) 45.

[6] R.L.Hoffman, Trans. Soc. Rheol. 16 (1972) 155.

[7] R.L.Hoffman, J.Coll. Int. Sci. 46 (1974) 491.

[8] R.L.Hoffman, Adv.Colloid Interface Sci. 17 (1982) 161.

[9] N.B.Uriev and I.Ya.Ladyzhinski, Kolloidn. Zh. 54 (1992) 87.

[10] I.Ya.Ladyzhinski, G.N.Urieva, J.Mewis and N.B.Uriev, Kolloidn.Zh. 54 (1992) 91, 97.

[11] B.A.Firth and R.J.Hunter, J. Coll. Int. Sci. 57 (1976) 248, 266.

[12] B.A.Firth, J. Coll. Int. Sci. 57 (1976) 257.

[13] R.J.Hunter and J.Frayne, J. Coll. Int. Sci. 76 (1980) 107.

[14] R.Buscall, P.D.A.Mills and G.E.Yates, Colloids and Surfaces 18 (1986) 341.

[15] R.Buscall, P.D.A.Mills J.W.Goodwin and D.W.Lawson, J. Chem. Soc. Faraday Transactions I, 34 (1988), 4249.

[16] R.M.Pashley and J.N.Israelachvili, Colloids and Surfaces 2 (1981), 169

[17] Z.Xu and R.H.Yoon, J.Coll.Int.Sci. 134 (1990), 427

[18] F.Groeneweg, F.van Voorst Vader, W.G.M.Agterof, Chem.Eng.Sci. 48 (1993), 229.

[19] F.W.A.M.Schreuder, A.J.G. van Diemen and H.N.Stein, J. Coll. Int. Sci. 111 (1986), 35.

[20] R.J.Akers and G.P.Machin, Preprints, 2nd World Filtration Congress, 1979, p. 365.

[21] W.Boersma, P.J.M.Baets, J.Laven, H.N.Stein, J.Rheology 35 (1991) 1093. 